\title{
Damping of high-rise structure vibrations with viscoelastic dynamic dampers
}

\author{
$M$ Mirsaidov $^{1, *}, R$ Abdikarimov $^{2}, S h$ Khudainazarov $^{1}, T$ Sabirjanov $^{3}$ \\ ${ }^{1}$ Tashkent Institute of Irrigation and Agricultural Mechanization Engineers, 39, Kori Niyoziy str., \\ 100000, Tashkent, Uzbekistan \\ ${ }^{2}$ Tashkent Institute of Finance, Tashkent, Uzbekistan \\ ${ }^{3}$ Fergana Polytechnic Institute, Fergana, Uzbekistan
}

\begin{abstract}
The paper is devoted to the study of dissipative properties of inhomogeneous viscoelastic systems of structures with dynamic vibration dampers. A detailed analysis of well-known studies concerning this problem is given. A mathematical model, technique and algorithm for studying the dissipative properties of inhomogeneous viscoelastic systems of high-rise buildings with dynamic vibration dampers are developed in the paper, taking into account the real geometry of structures. The hereditary BoltzmannVolterra theory was used to describe the viscoelastic properties of the damper and springs material. To solve the problem, the finite element method and the Muller method were used. The natural vibration modes of the Novo-Angren TPP smokestack with dynamic vibration dampers were investigated for various damper parameters. The imaginary part of complex eigenfrequency of the system was used as a dissipative index. A number of new mechanical effects were identified. The developed technique can be used to optimize the parameters of a viscoelastic damper for a structure.
\end{abstract}

\section{Introduction}

The problem of reducing the vibrations level of structural units is associated with the need to increase their strength and protect them from the harmful effect of vibrations.

To date, various methods and means of dealing with unacceptable vibrations of structures are known, in particular, a change in stiffness and inertial parameters of structures in order to detune from resonances, an increase in damping properties by using materials and structures with high absorbing ability, for example, special coatings, vibration isolation and vibration dampers [1-5]. Each of the methods mentioned has its own rational area of application. A special place in solving this problem belongs to dynamic vibration dampers (DVD).

One of the important aspects of research in the field of vibration protection of a structure is to define the possibilities of increasing the efficiency of vibration damping by complicating the DVD design or maintaining the same efficiency while simplifying the design of the DVD damping element.

\footnotetext{
* Corresponding author: mirsaidov1948@mail.ru
} 
The main task in projecting real structures with DVD is the necessity to optimize the damper parameters, which provide the greatest damping level of structure vibrations.

To assess the efficiency of a structure system with dampers, it is necessary to study the natural vibrations of dissipative systems, i.e. the most ordered motion of the system, occurring in the absence of external excitations. In this case, the dissipative system oscillates according to a harmonic law with a complex eigenfrequency; the real part of this complex frequency means the system oscillation frequency, and the imaginary part determines the rate of oscillation damping and is, in the sense, the damping coefficient.

In [1-7], much attention was paid to assess the effectiveness and to determine the optimal parameters of dynamic dampers for various structures and buildings.

Along with it:

- in [8], it was proposed, on the basis of a reliable mathematical model ICA, to efficiently calculate the eigenfrequency and damping coefficient of oscillations using the probability distribution function of eigenfrequency;

- a frequency-based optimization method to find design variables such as mass, period and damping coefficient of the tuned mass damper on the top of the structure was presented in [9];

- in [10] the reduction of wind vibrations of a flexible structure with low internal damping was considered. Optimal mechanical properties of a damper with a mass to damp vibrations of high-rise buildings were investigated;

- a new multidimensional device for isolation and mitigation of earthquake consequences was developed and tested in [11]. The influence of the excitation frequency and ambient temperature on the horizontal properties of this device was investigated;

- in [12], the control characteristics of the Smart Outrigger damper system were investigated to reduce wind and seismic impact. Numerical analysis showed that the Smart Outrigger damper system can provide superior control performance to reduce wind and seismic impact; - the high-rise building vibrations caused by wind were investigated in [13], taking into account the influence of vortices created by different flows. The vibration level of a structure with a damper under wind load was investigated both with the emerging vortices and without them;

- in [14-15], the models and methods of calculation were developed and the dynamics of the "high-rise structure - nonlinear damper - viscoelastic foundation" system was investigated; it allowed changing the input parameters of various design schemes and the loading options.

Along with this, a number of publications were devoted to the study of the dynamics of various inhomogeneous systems, taking into account their features and operating conditions, in which the behavior of various structures under dynamic loading was evaluated [16-30].

Here is just a brief overview of some works devoted to the vibration study of a structure with dynamic dampers and the dynamics of various inhomogeneous systems.

Despite the numerous available publications on this issue, the study of the effectiveness of damping ability of inhomogeneous systems, i.e. the structures with viscoelastic dynamic dampers is an urgent task.

\section{Mathematical model of the problem}

Bending natural vibrations of high-rise buildings (Figure 1) with annular cross-section F (z) and a piecewise constant slope of the generatrix are considered in the paper. The building material has viscoelastic properties. Dynamic vibration dampers $\mathrm{m}_{\mathrm{k}}(\mathrm{k}=1,2, \ldots, \mathrm{N})$ are installed at various levels of the structure. 


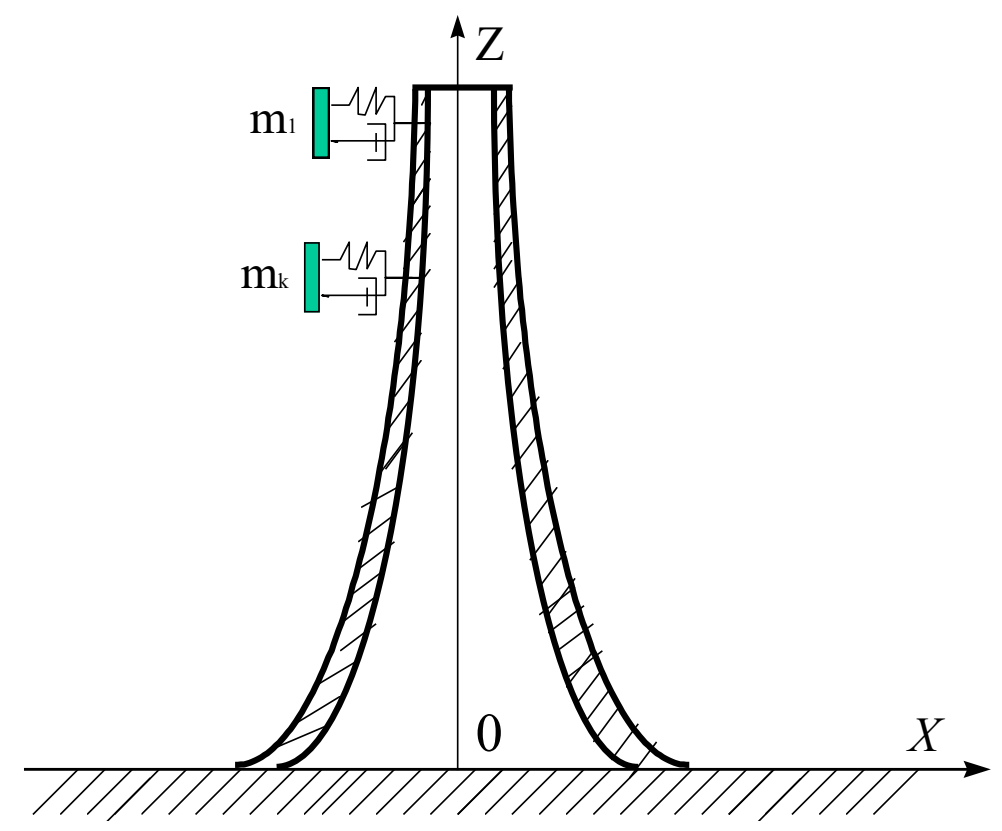

Fig. 1. Model of a high-rise structure with dynamic vibration dampers.

To describe the viscoelastic properties of the structure material, the linear hereditary Boltzmann-Volterra theory $[31,32]$ was used, according to which the relationships between stress $\sigma_{\mathrm{z}}$ and strain $\varepsilon_{\mathrm{z}}$ have the form:

$$
\begin{gathered}
\tilde{\sigma}_{z}(t)=\tilde{E} \times\left[\varepsilon_{z}(t)\right] \\
\tilde{E}[\varphi(t)]=E\left[\varphi(t)-\int_{0}^{t} R_{1}(t-\tau) \varphi(\tau) d \tau\right]
\end{gathered}
$$

where $\mathrm{E}$ is the instantaneous modulus of elasticity and $\mathrm{R}_{1}(\mathrm{t})$ is the relaxation kernel of the structure material; $\varphi(t)$ is an arbitrary function of time.

The relationship between the deflection of the structure point $\mathrm{w}$ and strain $\varepsilon_{\mathrm{z}}$ is taken as

$$
\varepsilon_{z}=-x \frac{\partial^{2} w}{\partial z^{2}}
$$

and the relationship between the bending moment $\mathrm{M}_{\mathrm{z}}$ and the stress $\sigma_{\mathrm{z}}$ has the form

$$
\tilde{M}_{z}=\int_{F} x \tilde{\sigma}_{z} d F
$$

where $\mathrm{F}(\mathrm{z})$ is the cross-sectional area of the structure.

For the mathematical statement of the problem, the kinematic boundary condition was used - 


$$
z=0: \quad \mathrm{w}(\mathrm{z}, \mathrm{t})=0 ; \quad \frac{\partial w}{\partial z}=0
$$

and the principle of virtual displacements, according to which the sum of the work of all active forces, including inertial ones, on a virtual displacement $\delta \mathrm{w}$, satisfying the geometrical boundary conditions, is zero, i.e.

$$
\delta \mathrm{A}_{\mathrm{m}}+\delta \mathrm{A}_{\mathrm{u}}+\delta \mathrm{A}_{\mathrm{n}}+\delta \mathrm{A}_{\mathrm{uu}}=0
$$

Here $\delta \mathrm{A}_{\mathrm{m}}, \delta \mathrm{A}_{\mathrm{u}}$ are the virtual work of the bending moment and inertia forces of the structure; $\delta A_{n}, \delta A_{u u}$ - virtual work of inertial forces of added mass $m_{k}$, elastic and viscoelastic forces arising in the DVD elements. These works are calculated as follows:

$$
\begin{gathered}
\delta \mathrm{A}_{\mathrm{m}}=-\int_{0}^{\mathrm{H}} \widetilde{\mathrm{M}}_{\mathrm{z}} \delta\left(\frac{\partial^{2} \mathrm{w}}{\partial \mathrm{z}^{2}}\right) \mathrm{dz} ; \delta \mathrm{A}_{\mathrm{u}}=-\rho \int_{0}^{\mathrm{H}} \mathrm{F}(\mathrm{z})\left(\frac{\partial^{2} \mathrm{w}}{\partial \mathrm{t}^{2}}\right) \delta \mathrm{wdz} ; \\
\delta \mathrm{A}_{\mathrm{n}}=-\sum_{\mathrm{k}=1}^{\mathrm{N}} \mathrm{m}_{\mathrm{k}} \ddot{\mathrm{w}}_{\mathrm{k}} \delta \mathrm{w}_{\mathrm{k}} ; \quad \delta \mathrm{A}_{\mathrm{uu}}=-\sum_{\mathrm{k}, \mathrm{l}=1}^{\mathrm{N}} \widetilde{\mathrm{K}}_{\mathrm{kl}} \mathrm{w}_{\mathrm{k}} \delta \mathrm{w}_{1}, \\
J(z)=\frac{\pi}{64}\left(D^{4}(z)-d^{4}(z)\right), \\
F(z)=\frac{\pi}{4}\left(D^{2}(z)-d^{2}(z)\right)
\end{gathered}
$$

Here $w(z, t)$ is the deflection of the neutral line at a point $z ; \rho$ is the density of the building material; J (z), F (z), D, d, H are the moment of inertia, cross-sectional area, outer diameter, inner diameter and the height of the structure, respectively; $\mathrm{N}$ is the number of added mass.

If the damper elements have viscoelastic properties, then they are described using an integral operator of the form:

$$
\tilde{K}_{k l}=K_{k l}\left[\varphi(\mathrm{t})-\int_{0}^{\mathrm{t}} \mathrm{R}_{2}(\mathrm{t}-\tau) \varphi(\tau) \mathrm{d} \tau\right],
$$

where $K_{k l}$ is the instantaneous stiffness of the damper; $\varphi(t)$ is an arbitrary function of time; $\mathrm{m}_{\mathrm{k}}$ is the added mass of dampers.

It is required to find such motion of a structure with a DVD, in which each point of it performs harmonic oscillations of a frequency $\omega$ and an amplitude $w^{*}(z)$, the values of which vary from point to point according to a complex harmonic law, i.e.

$$
\mathrm{w}(\mathrm{z}, \mathrm{t})=\mathrm{w}^{*}(\mathrm{z}) \mathrm{e}^{-\mathrm{i} \omega \mathrm{t}}
$$

Here $\omega=\omega_{\mathrm{R}}-\mathrm{i} \omega_{\mathrm{I}}, \mathrm{w}^{*}(\mathrm{z})=\mathrm{w}_{\mathrm{R}}^{*}(\mathrm{z})-\mathrm{i \textrm {w } _ { \mathrm { I } } ^ { * }}(\mathrm{z})$ are the complex eigenfrequencies and vibration modes. 
In this case, the parameters reflecting the viscoelastic properties of the structure and damper material are replaced by approximate relations $[26,30,32]$

$$
\begin{aligned}
& \widetilde{\mathrm{E}} \cong \overline{\mathrm{E}}=\mathrm{E}\left[1-\mathrm{i} \Gamma_{1}^{\mathrm{s}}\left(\omega_{\mathrm{R}}\right)-\Gamma_{1}^{\mathrm{c}}\left(\omega_{\mathrm{R}}\right)\right] \\
& \widetilde{\mathrm{K}} \cong \overline{\mathrm{K}}=\mathrm{K}\left[1-\mathrm{i} \Gamma_{2}^{\mathrm{s}}\left(\omega_{\mathrm{R}}\right)-\Gamma_{2}^{\mathrm{c}}\left(\omega_{\mathrm{R}}\right)\right]
\end{aligned}
$$

where $\Gamma_{1}^{s}, \Gamma_{1}^{c}, \Gamma_{2}^{s}, \Gamma_{2}^{c}$ are the sine and cosine Fourier images of the relaxation kernels $\mathrm{R}_{1}$ and $\mathrm{R}_{2}$, determined by:

$$
\begin{aligned}
& \Gamma_{1}^{c}\left(\omega_{R}\right)=\int_{0}^{\infty} R_{1}(t) \cos \left(\omega_{R} \tau\right) d \tau, \quad \Gamma_{1}^{s}\left(\omega_{R}\right)=\int_{0}^{\infty} R_{1}(t) \sin \left(\omega_{R} \tau\right) d \tau, \\
& \Gamma_{2}^{c}\left(\omega_{R}\right)=\int_{0}^{\infty} R_{2}(t) \cos \left(\omega_{R} \tau\right) d \tau, \quad \Gamma_{2}^{s}\left(\omega_{R}\right)=\int_{0}^{\infty} R_{2}(t) \sin \left(\omega_{R} \tau\right) d \tau
\end{aligned}
$$

Substitution of (9) into (1) - (8) leads the problem under consideration to a complex variational eigenvalue one

$$
\int_{0}^{\mathrm{H}} \overline{\mathrm{M}}_{\mathrm{z}} \delta\left(\frac{\mathrm{d}^{2} \mathrm{w}^{*}}{d \mathrm{z}^{2}}\right) \mathrm{dz}+\rho \omega^{2} \int_{0}^{\mathrm{H}} \mathrm{F}(\mathrm{z}) \mathrm{w}^{*} \delta \mathrm{w}^{*} \mathrm{dz}+\omega^{2} \sum_{\mathrm{k}=1}^{\mathrm{N}} \mathrm{m}_{\mathrm{k}} \mathrm{w}_{\mathrm{k}}^{*} \delta \mathrm{w}_{\mathrm{k}}^{*}+\sum_{\mathrm{k}, \mathrm{l}=1}^{\mathrm{N}} \overline{\mathrm{K}}_{\mathrm{kl}} \mathrm{w}_{\mathrm{k}}^{*} \delta \mathrm{w}_{1}^{*}=0
$$

with boundary conditions

$$
z=0: \quad w^{*}=0 ; \quad w^{1 *}=0
$$

Thus, the problem of finding complex eigenfrequencies $\omega=\omega_{R}-i \omega_{I}$ and complex natural modes of vibrations $w^{*}(z)$ of the system under consideration (Fig. 1) was reduced to finding a constant $\omega$ and a function $w^{*}(z)$, that satisfy equation (12) and conditions (13) for any kinematic virtual displacement $\delta w^{*}$.

In non-conservative systems, the real part $\omega_{R}$ of the complex eigenfrequency $\omega=\omega_{R}-i \omega_{I}$ means the frequency of the system oscillations, and the imaginary part $\omega_{I}$ determines the rate of oscillation damping and has the meaning of a damping coefficient.

In this case, the logarithmic decrement of oscillations for the system under consideration can be determined using the formula $\delta=-2 \pi \frac{\omega_{I}}{\omega_{R}}$.

\section{Solution methods}

The considered problem (12) and (13) is solved by the finite element method. When discretizing structures, a one-dimensional finite element in the form of a truncated cone with a cubic approximation of the displacement field inside the element was used. 
The execution of the procedure by the finite element method (FEM) leads the variational problem (12) - (13) to a complex algebraic eigenvalue problem of the form:

$$
\left([\bar{K}]-\omega^{2}[M]\right)\{x\}=0
$$

Here: $\quad[\bar{K}]$ is the complex matrix of structure rigidity, the elements of which depend on $\omega_{R} ; \quad[M]$ is the mass matrix of the structure; $\omega=\omega_{R}-i \omega_{I},\{x\}=\left\{x_{R}\right\}-i\left\{x_{I}\right\}$ are the complex eigenfrequency and the vector, respectively.

The dimension of the resulting equations (14) depends on the number of finite elements into which the structure is divided, plus as many equations are added as there are the added masses attached to the beam as part of the DVD.

The complex eigenfrequency of problem (14) is determined by the Muller method [33] and the eigenvector by the Gauss method or the square root method [34].

In dynamic calculation of structures, the knowledge of only a few lower complex frequencies and modes of vibration is generally sufficient. An effective method for solving this class of problems is the Muller method [33], the main advantage of which is the ability to determine the required number of lower frequencies without determining the coefficients of the characteristic equation (14) in an explicit form. In this case, only the calculation of characteristic determinant of equation (14) is required at fixed values of $\mathrm{I} \lambda=\omega^{2}$. The preparatory stage of the method is the use of the square root method [34] in the decomposition matrices $[\bar{K}]$ and $[M]$ in the form of a product of two triangular matrices and the representation of the characteristic determinant in the form:

$$
P(\lambda)=\left|[\bar{K}]^{T}[\bar{K}]-\lambda[M]^{T}[M]\right|=0
$$

The basis of the Muller method is represented by the iterative method in combination with parabolic interpolation of the characteristic determinant (15). The essence of the method is as follows.

Based on three arbitrarily specified values of $\lambda_{0}, \lambda_{1}, \lambda_{2}$, the corresponding values of the characteristic determinant are calculated as in (15):

$$
P\left(\lambda_{0}\right)=t_{0}, \quad P\left(\lambda_{1}\right)=t_{1}, \quad P\left(\lambda_{2}\right)=t_{2}
$$

The found values are used to construct the systems of interpolation equations of the second degree:

$$
\left\{\begin{array}{l}
b_{0} \lambda_{0}^{2}+b_{1} \lambda_{0}+b_{2}=t_{0} \\
b_{0} \lambda_{1}^{2}+b_{1} \lambda_{1}+b_{2}=t_{1} \\
b_{0} \lambda_{2}^{2}+b_{1} \lambda_{2}+b_{2}=t_{2}
\end{array}\right.
$$

whence the coefficients $b_{0}, b_{1}, b_{2}$, used to construct the next interpolation equation of the second degree, are determined as

$$
b_{0} \lambda^{2}+b_{1} \lambda+b_{2}=0
$$


The choice of the interpolation polynomial of the second degree (and not the first or higher one) is due to the fact that it allows entering the plane of complex numbers with real axis without significant complications, even if the coefficients $P(\lambda)$ and the initial approximations are the real ones.

The root of equation (18), close in modulus to value of $\lambda_{2}$, is taken as the next approximation of $\lambda_{3}$ and the whole procedure is repeated for the given values of $\lambda_{1}, \lambda_{2}$, $\lambda_{3}$, as a result of which the value of $\lambda_{4}$ is obtained, etc. The sequence $\left\{\lambda_{n}\right\}$ converges to some root of equation (15), regardless of the choice of initial approximations of $\lambda_{0}, \lambda_{1}, \lambda_{2}$ . If $\lambda_{0}=-1, \lambda_{1}=0, \lambda_{2}=1$, then the sequence $\left\{\lambda_{n}\right\}$ is usually reduced to the smallest root of equation (15). The iterative process stops at

$$
\left|\frac{\lambda_{n}-\lambda_{n-1}}{\lambda_{n}}\right|<\varepsilon
$$

where $\varepsilon$ is some given positive value that characterizes the accuracy of the approximate root value.

After determining the first root of $\tilde{\lambda}_{1}$, it is separated from the characteristic determinant (15) by applying the order reduction formula:

$$
P(\lambda)=\frac{1}{\lambda-\widetilde{\lambda}_{1}}\left|[\bar{K}]^{T}[\bar{K}]-\lambda[M]^{T}[M]\right|=0
$$

Further, from the characteristic determinant (20), the power of which has decreased by one, the second root $\tilde{\lambda}_{2}$ of equation (15) is found by the above method with the same initial approximations. In this case, the found roots $\tilde{\lambda}_{1}, \tilde{\lambda}_{2}, \ldots, \tilde{\lambda}_{n}$ of equation (15) are the complex values. The complex eigenfrequencies $\omega_{1}, \omega_{2}, \ldots, \omega_{n}$ of problem (14) are calculated based on them. Further, substituting the found values of $\omega_{1}, \omega_{2}, \ldots, \omega_{n}$ into equation (14), the complex eigenforms $\left\{x_{1}\right\},\left\{x_{2}\right\}, \ldots\left\{x_{n}\right\}$ are found by the square root method.

\section{Results and discussion}

As a concrete example, a real high-rise smokestack of the Novo-Angren thermal power plant (TPP) was considered.

All geometrical dimensions of the smokestack of Novo-Angren TPP were taken from the design documentation: the smokestack height $\mathrm{H}=325.0 \mathrm{~m}$. Dimensions: at elevation: $\mathrm{z}=0.0$ $\mathrm{m}: \mathrm{R}=19.0 \mathrm{~m}, \mathrm{~h}=1.10 \mathrm{~m}$; at elevations: $\mathrm{z}=325.0 \mathrm{~m}: \mathrm{R}=8.35 \mathrm{~m}, \mathrm{~h}=0.40 \mathrm{~m}$.

The parameters of physical and mechanical characteristics of the structure material are taken as:

$E=2.9 \times 10^{4} \mathrm{MPa} ; \nu=0.17 ; \rho=2.5 \mathrm{t} / \mathrm{m}^{3}$. 
Here: $\mathrm{H}$ is the height, $\mathrm{R}$ - the outer diameter and $\mathrm{h}-$ the pipe wall thickness, $\mathrm{z}-$ the pipe elevations from the structure base; E, $\rho, v$ - the elastic modulus, density and Poisson's ratio, respectively.

\subsection{Accuracy estimation of the calculation method and algorithm}

Bending eigenfrequencies of the high-rise smokestack of the Novo - Angren TPP were determined, as a test example, in elastic statement without a damper, using the proposed technique and the results obtained were compared with the results of field experiments [35].

The results of comparison of the periods of flexural natural vibrations of a real high-rise pipe of the Novo-Angren TPP, $\left(\mathrm{T}_{\mathrm{i}}=\omega_{i} / 2 \pi\right)$ are: the ones obtained using the developed technique $-\mathrm{T}_{1}=3.26 \mathrm{~s}, \mathrm{~T}_{2}=0.91 \mathrm{~s}, \mathrm{~T}_{3}=0.38 \mathrm{~s}, \mathrm{~T}_{4}=0.21 \mathrm{~s}$ and certain periods of oscillations obtained in field experiments $-\mathrm{T}_{1}=3.4 \mathrm{~s}, \mathrm{~T}_{2}=1.0 \mathrm{~s}, \mathrm{~T}_{3}=0.5 \mathrm{sec}, \mathrm{T}_{4}=0.3 \mathrm{sec}$.

An analysis of these results shows that the values of the periods of bending vibrations obtained in field experiments [35] are quite close to the ones found theoretically using the developed technique.

\subsection{Assessment of the complex eigenfrequency of structures with dynamic dampers}

Consider the change in eigenfrequencies of the smokestack of the Novo-Angren thermal power plant (TPP) with a dynamic vibration damper installed at its upper mark $(\mathrm{z}=325 \mathrm{~m})$. Here the pipe with dampers is considered as an inhomogeneous system, i.e., if the structure material is visco-elastic, then the damper is elastic, or, if the material is elastic, then the damper is viscoelastic, etc.

The main problem in reducing the vibration amplitude of a structure using DVD is to optimize the damper parameters, to tune it to certain frequencies and to increase the damping ability of the structure with vibration dampers.

It is known [26, 30] that the greatest level of damping can be achieved only for inhomogeneous systems, i.e. when one part of the structure is elastic and the other is viscoelastic, or if both parts of the structure are viscoelastic, but of different viscoelastic properties.

When solving the problem of natural vibrations of a structure with a damper, the question of the damper tuning arises; it consists in the following: the mass associated with the structure (Figure 1) leads to a certain decrease in the frequencies of natural vibrations $\left(\omega_{1}, \omega_{2}, \ldots, \omega_{n}\right)$ of the structure. On the other hand, the damper has its own partial frequency. Thus, for the structure under consideration, in the vicinity of one of the fundamental natural frequencies (bringing the natural frequency of the damper closer to it), two close frequencies could be obtained. Let $\omega_{2}$ be the eigenfrequency of vibration damper. It is assumed that the damper must be tuned to the first eigenfrequency of the pipe $\omega_{1}$. The damper tuning consists in the maximum approximation of the values of these frequencies and it is achieved by changing (varying) the value of $\mathrm{K}_{11}$ - the damper stiffness.

Next, the problem of damping of the Novo-Angren TPP smokestack vibrations with dynamic vibration dampers installed at its upper elevation $(\mathrm{z}=325 \mathrm{~m})$ (Figure 1) according to the first mode was solved. If it is necessary to reduce vibrations according to the other mode, this can be done by choosing the stiffness $\mathrm{K}_{11}$. If it is required to damp several vibration modes at once, then a damper is used with several masses $m_{1}, m_{2}, m_{3}, \ldots$, for which the stiffness $\mathrm{K}_{11}, \mathrm{~K}_{22}, \mathrm{~K}_{33}, \ldots$ etc. is selected.

To tune the damper according to the first mode, its stiffness $\mathrm{K}_{11}$, mass $\mathrm{m}_{1}$, and viscoelastic parameters 
$\left(\Gamma_{2}^{\mathrm{s}}, \quad \Gamma_{2}^{\mathrm{c}}\right)$, that ensure energy dissipation, vary within different limits. At the first approximation, the smokestack is considered as an elastic structure (i.e., $\Gamma_{1}^{\tilde{n}}=0 ; \Gamma_{1}^{s}=0$ ), then the viscoelastic properties of the structure material are taken into consideration. When describing the viscoelastic properties of the structure material, the Koltunov - Rzhanitsyn relaxation kernel was used:

$$
\Gamma_{1}(t)=A e^{-\beta t} t^{\alpha-1}
$$

with the parameters of the relaxation kernel [35]: $A=0.00194 ; \beta=0.00000014 ; \alpha=0.075$. In the calculations, the following values of the damper mass were taken $\mathrm{m}_{1}=0.0004 \mathrm{M} ; \mathrm{m}_{1}=$ $0.001 \mathrm{M} ; \mathrm{m}_{1}=0.002 \mathrm{M}$ ( $\mathrm{M}$ is the pipe mass).

Then, the change in the complex eigenfrequencies of the smokestack with DVD was investigated at different values of viscosities of the structure and the DVD material, as well as at different values of mass $m_{1}$ and stiffness $K_{11}$ of the damper. In this case, the found real part $\omega_{R}$ of the complex eigenfrequency $\omega=\omega_{R}-i \omega_{I}$ allows estimating the frequency of free damped oscillations, and the imaginary part $\omega_{\text {I }}$ gives information about the damping coefficient of oscillations, i.e. determines the dissipative properties of a structure with the DVD, as a whole.

Figure 2 shows the change in real $\omega_{\mathrm{R}}$ and complex $\omega_{\mathrm{I}}$ parts of the complex eigenfrequency $\omega$ of the Novo-Angren TPP smokestack with dynamic vibration dampers. The pipe itself was considered as a viscoelastic structure, and the DVD - as an elastic single-mass structure (i.e. with parameters $\Gamma_{2}^{\mathrm{s}}=0, \Gamma_{2}^{\mathrm{c}}=0$ ), installed at a pipe height $\mathrm{z}=325 \mathrm{~m}$. The presented results (Figure 2) show the change in two close frequencies of a single system - a structure with the DVD (Figure 1). The first frequency of the system $\omega_{1}$ corresponds to the eigenfrequencies of a viscoelastic structure (pipe), and the second frequency $\omega_{2}$ - to the eigenfrequencies of a single-mass elastic damper. Consider the change in these frequencies for different values of mass $\mathrm{m}_{1}$ and the damper stiffness $\mathrm{K}_{11}$.

The nature of the change in eigenfrequencies versus stiffness $K_{11}$ showed (Figure 2) that it has the form of a Wien diagram for the partial frequencies of a multi-mass system, i.e. with an increase in the rigidity $K_{11}$, the real parts $\omega_{1 R}, \omega_{2 R}$ of the complex eigenfrequencies $\omega_{1}$ and $\omega_{2}$ asymptotically approach each other (Figure $2 \mathrm{a}$ ), and then diverge.

$\mathrm{m}_{1}=0.0004 * \mathrm{M}$.

a. $\omega_{\mathrm{R}}$

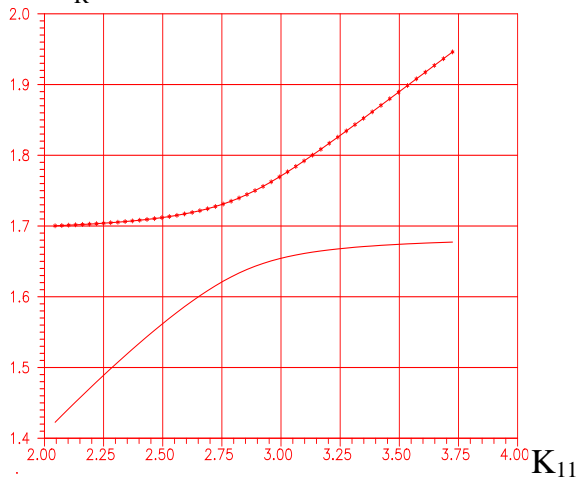

b. $\omega_{\text {I }}$

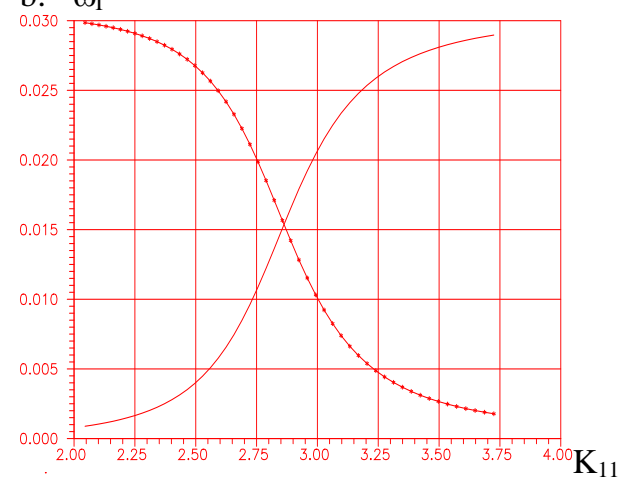

Fig. 2. Changes in the components of complex eigenfrequency of a viscoelastic pipe of the NovoAngren TPP with the DVD at different values of the stiffness of elastic damper: —— damper; ————- - pipe. 
As for the imaginary parts $\omega_{1 \mathrm{I}}, \omega_{2 \mathrm{I}}$, up to a certain value of $K_{11}$, they approach each other and intersect, and at further increase in stiffness $K_{11}$, they sharply diverge (Figure $2 b$ ). This means that the DVD in the given spectral domain, (i.e. at high values of $K_{11}$ ) has the greatest dissipative ability.

The pattern shown in Figure 2, the approach of eigenfrequencies and their subsequent divergence when changing the parameters of the "structure-damper" system, is characteristic of weakly coupled systems and is explained by the interaction of close natural modes of vibration.

The results (Figure 2) show that the values of real parts $\omega_{1 R}, \omega_{2 R}$ of the above complex frequencies $\omega_{1}$ and $\omega_{2}$ have the maximum approximation at $\omega_{11} \approx \omega_{2 I}$.

Despite the fact that the damper is elastic, it has the highest dissipative properties at certain values of the spring stiffness. This is due to the energy transfer from one object to another in a coupled system "structure-damper" (Figure 2b). The studies carried out at various values of the damper mass showed that the less the damper mass, the higher the energy transfer rate (Figure 2b). An increase in the damper mass leads to a weakening of the structure - damper connection.

These studies do not entirely confirm the statement given in $[26,30]$, that in structurally inhomogeneous systems when two or more eigenfrequencies approach each other, it is possible to achieve a sharp increase in the damping rate of certain vibration modes of the structure due to the interaction of close natural vibration modes of the structure and the damper. In fact, with an increase in the damper stiffness, the dissipative ability of the damper increases due to a decrease in these properties of the structure.

Figure 3 shows the change in real $\omega_{R}$ and complex $\omega_{\text {I }}$ parts of the eigenfrequency of the Novo-Angren TPP smokestack with the DVD, obtained at different values of stiffness $\mathrm{K}_{11}$ and viscoelastic properties $\Gamma_{2}^{\mathrm{s}}, \quad \Gamma_{2}^{\mathrm{c}}$ of the damper spring. In this case, the structure itself was considered as an elastic structure, and the DVD as a viscoelastic structure of a mass $\mathrm{m}_{1}$ $=0.004 \mathrm{M}$ located at the pipe height of $\mathrm{z}=325 \mathrm{~m}$.

These results (Figure 3 ) confirm the above conclusions that energy in an inhomogeneous system is transferred from one body to another. If the spring stiffness of the damper is small, then the system is almost uncoupled (Figure 3a). In this case, $\omega_{1 R}-$ the eigenfrequency of a pipe with the DVD - corresponds to the eigenfrequency of an elastic pipe without a damper, i.e. $\omega_{11} \approx 0$ (Figure $3 b$ ). A study at various values of the viscosity parameters showed that an increase in the spring viscosity of the damper leads to an increase in the pipe - damper connection, to a more intense energy transfer from one body to another and to an increase in the dissipative properties $\left(\omega_{\mathrm{I}}\right)$ of the pipe with the DVD (Figure $3 \mathrm{~b}$ ).

$$
\Gamma_{2}^{\mathrm{c}}=0.1 ; \Gamma_{2}^{\mathrm{s}}=0.01
$$




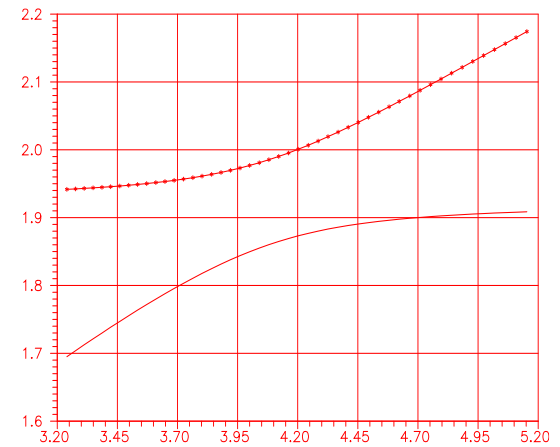

$\mathrm{K}_{11}$

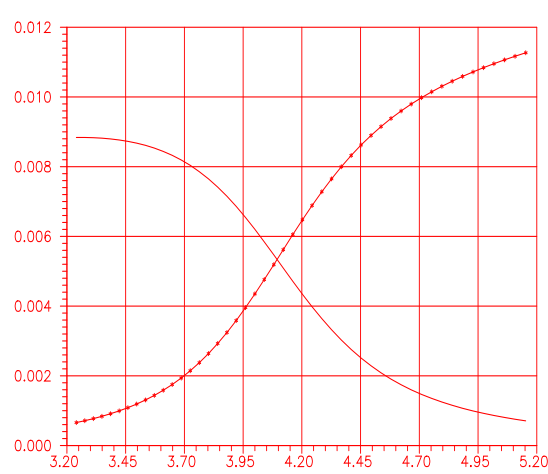

$\mathrm{K}_{11}$

Fig. 3. Changes in the components of the complex eigenfrequency of the Novo-Angren TPP elastic pipe with the DVD of mass $m_{1}=0.0004 \mathrm{M}$ at different values of the damper spring stiffness and viscosity:--- — damper; —*—*- pipe.

The highest rate of energy transfer occurs when the real parts of the first $\omega_{1}$ and second $\omega_{2}$ complex frequencies of the pipe with the DVD approach each other.

Figure 4 shows the results of the change in $\omega_{R}$ and $\omega_{I}$ for a viscoelastic pipe with a viscoelastic damper $\left(\Gamma_{2}^{\tilde{n}}=0,2 ; \Gamma_{2}^{s}=0,02\right)$, installed at the pipe height $\mathrm{z}=325 \mathrm{~m}$. Various studies were carried out to assess the efficiency of vibration damping of the considered systems depending on the value of mass $m_{1}$ and the spring stiffness of the damper $\mathrm{K}_{11}$. It was assumed that the pipe and the damper springs have different viscoelastic properties.

$\mathrm{m}_{1}=0.0004 * \mathrm{M} ; \Gamma_{2}^{\mathrm{c}}=0.2 ; \Gamma_{2}^{\mathrm{s}}=0.02$

a. $\omega_{\mathrm{R}}$

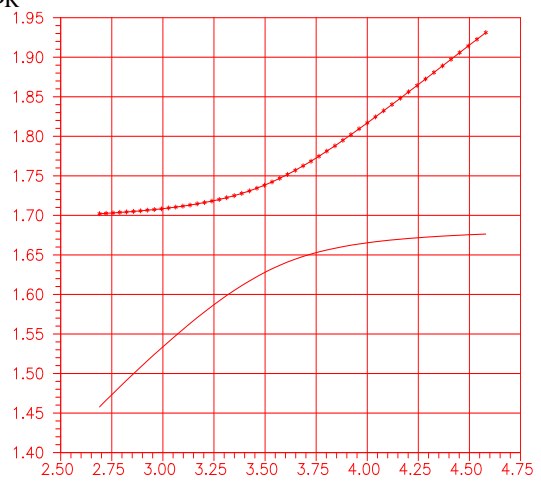

$\mathrm{K}_{11}$ b. $\omega_{\mathrm{I}}$

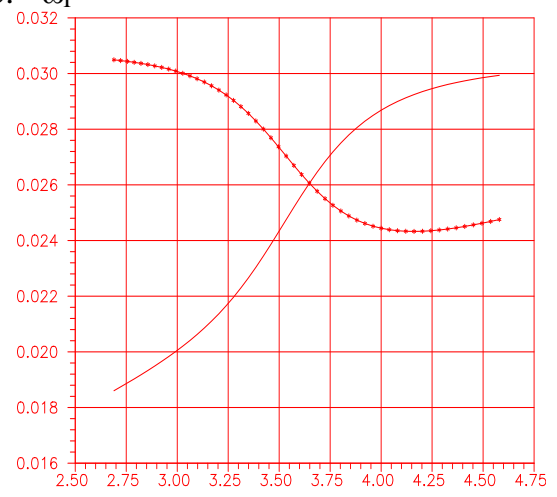

$\mathrm{K}_{11}$

Fig. 4. Changes in the components of the complex eigenfrequency of the Novo-Angren TPP viscoelastic pipe with a viscoelastic DVD at different values of the mass and spring viscosity of the damper:-

- damper; —* — - - - - pipe.

The results obtained for different values of the damper mass and viscosity showed that an increase in the damper mass reduces the pipe with the DVD to a weakly coupled system. The change in $\omega_{I}$ shows that in this case when the energy transfer from one body to another is weakly expressed, the change in $\omega_{1 \mathrm{I}}$ and $\omega_{2 \mathrm{I}}$ at further increase in spring stiffness (after the approach of $\omega_{1 \mathrm{R}}$ and $\omega_{2 \mathrm{R}}$ ) does not lead to a sharp increase or decrease in $\omega_{\mathrm{I}}$, they remain at the same value. Here, with an increase in the damper stiffness, the dissipative ability of the damper increases, and the dissipative ability of the structure decreases. 
Figure 5 shows the results of changes in $\omega_{R}$ and $\omega$ of the Novo-Angren viscoelastic pipe with a viscoelastic DVD installed at a height of $\mathrm{z}=325 \mathrm{~m}$, depending on the viscoelastic properties and spring stiffness of the damper. Here, the mass of the damper did not change and was equal to $\mathrm{m}_{1}=0.0004 \mathrm{M}$. As the results show, when the viscous properties of the damper are less than the viscous properties of the pipe (after the frequencies $\omega_{1 R}$ and $\omega_{2 R}$ approach each other), energy is transferred from the pipe to the damper (Figure 5).

$\Gamma_{2}^{\mathrm{c}}=0.4 ; \Gamma_{2}^{\mathrm{s}}=0.04$

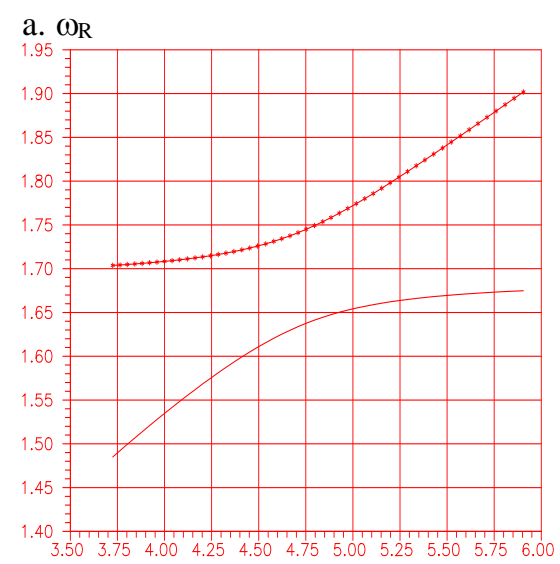

$\mathrm{K}_{11}$

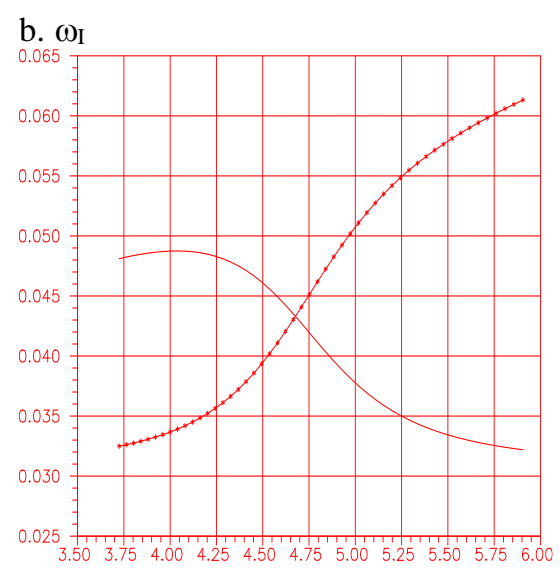

$\mathrm{K}_{11}$

Fig. 5. Change in the components of the complex eigenfrequency of the Novo-Angren TPP viscoelastic pipe with a viscoelastic DVD of mass $m_{1}=0.0004 \mathrm{M}$ at different values of spring stiffness and viscosity of the damper: — - damper; —* - — - - pipe.

If the viscous properties of the pipe and the damper are the same, then there is no transfer of dissipative properties from one body to another, as the system is a homogeneous one (Figure 5). If the viscous properties of the damper spring are greater than the viscous properties of the pipe, then after the frequencies $\omega_{1 R}$ and $\omega_{2 R}$ approach each other, the dissipative properties transfer from the damper to the pipe (Figure 5). In this case, the dissipative properties of the damper increase, and the dissipative properties of the structure decrease.

Studies have shown that to increase the dissipative ability of an elastic structure with dampers, the greatest effect can be obtained using a viscoelastic damper. To evaluate the efficiency of vibration damping in structure-damper inhomogeneous systems, it is necessary to use this technique in each case.

\section{Conclusions}

1. A mathematical model was developed to assess the dissipative ability of an inhomogeneous system of a structure with dynamic vibration dampers in a one-dimensional statement, taking into account the viscoelastic properties of the structure and damper material.

2. The hereditary Boltzmann-Volterra theory of viscoelasticity was used to account for the viscoelastic properties of the structure and damper material.

3. A technique and an algorithm were developed for determining the complex eigenfrequencies of inhomogeneous viscoelastic systems of a structure with the dampers using the finite element method and the Muller method. 
4. The reliability of the developed methodology and algorithm was verified by comparing the obtained results with the results of field experiments.

5. The imaginary part $\omega I$ of the complex eigenfrequencies $\omega=\omega_{R}-i \omega_{I}$ of the considered system was used as an index of dissipative properties.

6. Natural vibrations of the Novo-Angren TPP smokestack with dynamic vibration dampers were investigated for various viscous properties of the structure material and damper springs; this made possible to reveal a number of new mechanical effects.

7. The developed technique will make it possible to determine the optimal parameters of the damper for effective damping of vibrations in inhomogeneous structure - damper systems.

\section{References}

1. Eliseev S V, Nerubenko G 1982 Dynamic vibration dampers (Novosibirsk: Nauka)

2. Korenev B G, Reznikov L M 1988 Dynamic vibration dampers. Theory and technical applications (Nauka)

3. Dukart A V, Oleinik A I 2015 Dynamic dampers of structure vibrations (Publishing house Association of building universities)

4. Korenev B G, Blekherman A I 1979 Experience of tower structure vibrations damping

5. Korenev B G, Volotskiy M Ya, Fuks O M Struct. Mech. Struct. Des. 1-62 (1976)

6. Legeza V P, Akhmetov Y G 2006 Mech. Rigid Body 456

7. Legeza V P 2013 Mech. Rigid Body 265

8. Hwang J S, Noh J T, Lee S H, Kareem A 2019 Int. J. Concr. Struct. Mater. https://doi.org/10.1186/s40069-018-0319-7

9. Nigdeli S M, Bekdaş G 2017 KSCE J. Civ. Eng. https://doi.org/10.1007/s12205-0160829-2

10. Ramezani M, Bathaei A, Ghorbani-Tanha A K 2018 Earthq. Eng. Eng. Vib. https://doi.org/10.1007/s11803-018-0483-4

11. Zhao Dong, Xu Xiao, Zeng Xing, Huai Huang, Li Heng 2010 China Technol. Sci. 53 2658

12. Kang Hyun-Su, Kim J-W 2017 Int. J. Steel Struct. 171263

13. Momtaz A A, Abdollahian M A, Farshidianfar A 2017 Int. J. Adv. Struct. Eng. https://doi.org/10.1007/s40091-017-0174-9

14. Zemtsova O G 2011 Reg. Archit. Constr. 283

15. Zemtsova O G 2011 News South-West State Univ. 5(2) 385

16. Teshaev M, Safarov I I, Mirsaidov M 2019 J. Serbian Soc. Comput. Mech. https://doi.org/10.24874/jsscm.2019.13.02.08

17. Khodzhaev D A, Abdikarimov R A, Mirsaidov M 2019 M Mag. Civ. Eng. https://doi.org/10.18720/MCE.91.4

18. Maiboroda V P, Troyanovskiy I E, Safarov I I 1983 Reports Acad. Sci. USSR. Ser. "Mechanical Eng. 346

19. Ishmatov A N, Mirsaidov M 1991 Sov. Appl. Mech. https://doi.org/10.1007/BF00896519

20. Usarov M, Salokhiddinov A, Usarov D M, Khazratkulov I, Dremova N 2020 IOP Conf. Ser. Mater. Sci. Eng. https://doi.org/10.1088/1757-899x/869/5/052037

21. Mirsaidov M, Teshaev M, Ablokulov S, Rayimov D 2020 IOP Conf. Ser. Mater. Sci. Eng. https://doi.org/10.1088/1757-899x/883/1/012100 
22. Maiboroda V P, Troyanovsky I E 1983 Reports AN SSSR. Ser. Mech. Rigid Body 2117

23. Koltunov M A, Mirsaidov M, Troyanovskii I E 1978 Polym. Mech. https://doi.org/10.1007/BF00857468

24. Abdikarimov R A, Khodzhaev D A 2014 Mag. Civ. Eng. https://doi.org/10.5862/MCE.49.9

25. Mirsaidov M M, Abdikarimov R A, Khodzhaev D A 2019 PNRPU Mech. Bull. https://doi.org/10.15593/perm.mech/2019.2.11

26. Loginov P V, Salikhova Z R, Sultanov K $\quad$ S 2019 Mech. Solids https://doi.org/10.3103/S0025654419060074

27. Bakhodirov A A, Ismailova S I, Sultanov K S 2015 J. Appl. Math. Mech. https://doi.org/10.1016/j.jappmathmech.2016.04.005

28. Usarov M, Mamatisaev G, Toshmatov E, Yarashov J 2020 Journal of Physics: Conference Series https://doi.org/10.1088/1742-6596/1425/1/012004

29. Mirsaidov M, Safarov I, Teshaev M 2020 E3S Web of Conferences https://doi.org/10.1051/e3sconf/202016414013

30. Mirsaidov M, Nosirov A, Nasirov I 2020 E3S Web of Conferences https://doi.org/10.1051/e3sconf/202016402009

31. Rzhanitsyn A R 1968 Creep theory (Moscow: Stroyizdat)

32. Koltunov M A, Kravchuk A S, Maiboroda V P 1983 Applied Mechanics of Deformable Solids (Moscow: Higher school)

33. Muller D E 1956 Math. Tables Other Aids to Comput https://doi.org/10.2307/2001916.

34. Amosov A A, Dubinsky Yu A 2014 K.N.V.: Computational methods (St. Petersburg: "Lan")

35. Mirsaidov M M, Khudainazarov S O 2020 Mag. Civ. Eng. 96118 https://doi.org/DOI: 10.18720/MCE.96.10 